\title{
Consequences of FFP3 mask usage on venous blood gases
}

\author{
Gokhan Yalciner $^{1}$ (D) $\cdot$ Mehmet Ali Babademez ${ }^{2} \cdot$ Fatih Gul $^{2} \cdot$ Serkan Serifler ${ }^{2} \cdot$ Kadir Sinasi Bulut $^{2} \cdot$ Levent Ozturk $^{3}$
}

Received: 27 October 2020 / Accepted: 14 December 2020 / Published online: 18 January 2021

(C) Royal Academy of Medicine in Ireland 2021

\begin{abstract}
Objectives/hypothesis To investigate the effect of FFP3 mask usage on venous blood gases (VBG) and some subjective symptoms

Methods VBG analyses and subjective symptom questionary were obtained from 15 healthcare proffesionals before and after 4h FFP3 mask usage.

Results Wearing an FFP3 mask for 4 hours did not change any venous blood gas parameters between pre- and post-values, statistically. According to an 8-symptom questionary, only nausea did not show any significance. Headache, lightheadedness, visual difficulties, shortness of breath, palpitation, confusion, and difficult communication showed statistically significant difference between pre and post values.

Conclusion Four-hour use of FFP3 mask did not cause any significant VBG change. Although the participants complained about some subjective symptoms, this study indicated that long-term use of FFP3 mask did not cause any significant discomforts, and it was well tolerated.
\end{abstract}

Keywords Blood gas analysis $\cdot$ Filtering face piece respirator $\cdot$ Peripheral venous blood

\section{Introduction}

Lessons were learned on infection controls from past pandemics such as severe acute respiratory syndrome (SARS) in 2003, influenza A in 2009, and Middle East respiratory syndrome (MERS) in 2012 [1, 2]. These infection-control measures necessitate the use of protective filtering facepeace respirators (FFR) such as N95 masks for healthcare personnels $[1,2]$. Nowadays, FFR mask is widely used by healthcare professionals due to COVID-19 outbreak to protect themselves from secretions of people [3]. Depending on the total

This study has not been presented at any meeting.

Gokhan Yalciner

gkhnyalciner@gmail.com

Mehmet Ali Babademez

mababademez@gmail.com

Fatih Gul

drfatihgul@gmail.com

Serkan Serifler

serkanserifler@gmail.com

Kadir Sinasi Bulut

kadir.sinasi06@gmail.com leakage and filtering of the particle sizes up to $0.6 \mu \mathrm{m}$, respiratory masks ranging from FFP-1 to FFP-2 to FFP3 offer breathing protection for various concentrations of pollutants [4]. When working with pathogens such as viruses, bacteria, and fungal spores, FFP3 class respirator mask is recommended. Protection class FFP3 respiratory mask offers maximum protection from breathing air pollution. They filter $99 \%$ of all particles measuring up to $0.6 \mu \mathrm{m}$ [3].

Recently, the Food and Drug Administration (FDA) has published relevant criteria for masks that can be used by healthcare professionals according to the National Institute

Levent Ozturk

dr_levent@yahoo.com

1 Department of Otorhinolaryngology, Ankara City Hospital, Ankara, Turkey

2 Department of Otorhinolaryngology, Yıldırım Beyazıt School of Medicine, Ankara, Turkey

3 Department of Anesthesiology, Yildırım Beyazıt School of Medicine, Ankara, Turkey 
for Occupational Safety and Health (NIOSH) [5]. Despite widespread use in industry and by healthcare professionals, little is known about the effects of FFR masks for the respiratory function and subjective symptoms $[2,6,7]$. In this research, we investigated the effect of FFR mask on venous blood gases and subjective symptoms caused by mask use on volunteer doctors who routinely used FFP3 mask.

\section{Materials and methods}

Participants were 15 volunteer doctors ( 9 men and 6 women) whose ages were between 23 and 61 (mean 29.01 \pm 4.17 ) who are using FFP3 mask in daily working life at ENT clinic in city hospital. Exclusion criteria included smoking, obesity, and cardiopulmonary disease.

Written informed consent of the participants and ethical committee approval have been obtained. Venous blood samples were taken from the participants in the morning before working and after continuous 4-h working with FFP3 mask. All participants wore only one mask.

The participants also scored questionary (Roberge subjective symptoms [2]) which includes nausea, headache, lightheadedness, visual difficulties, shortness of breath, palpitation, confusion, and difficulty in communicating. Each symptom was scored between 1 and 5 (from not noticeable to very noticeable in the questionary).

\section{Statistical assessment}

SPSS version 25.0 (SPSS Inc., Chicago, IL) was used for statistical analysis. Paired $t$ test was used for pre and post differences in venous blood gas parameters and the subjective symptom questionary. Bar graph was used for the mean differences between pre and post $\mathrm{pO}_{2}$ and pre and post $\mathrm{CO}_{2}$ values.

\section{Results}

Fifteen ENT doctors participated in this study. None of them were obese as determined by having a BMI equal to or greater than 30 . The average mask-wearing time was $248 \mathrm{~min}$ ranged between 240 and $255 \mathrm{~min}$ (Table 1).

All doctors tolerated the use of respiratory masks for at least $4 \mathrm{~h}$. None of them removed the mask for any reason, either to eat or drink during the study period. Wearing an FFP3 mask for 4 hours did not change any venous blood gas parameters between pre and post values, statistically. The mean difference between pre- and post-pH, $\mathrm{pCO}_{2}, \mathrm{pO}_{2}$, and $\mathrm{SpO}_{2}$ values were $0.01,0.06,0.02$, and 1.78 , respectively (Table 2). The mean difference related to $\mathrm{pO}_{2}$ and $\mathrm{pCO}_{2}$ with confidence intervals is shown as bar graphs in Figs. 1 and 2.
Table 1 Characteristics of the study population

\begin{tabular}{llll}
\hline & \multicolumn{2}{l}{ Study group $(n=15)$} & \\
\cline { 2 - 4 } & $n$ & mean \pm SD & Range (min, max) \\
\hline Age, years & & $29.01 \pm 4.17$ & $23-61$ \\
Sex & & & \\
Female & 6 & - & \\
Male & 9 & - & $18-29$ \\
BMI, kg/m ${ }^{2}$ & & $24.04 \pm 2.44$ & $240-255$ \\
Mask wearing time, min & & $248.71 \pm 5.32$ & 240 \\
\hline
\end{tabular}

$B M I$ body mass index

According to an 8-symptom questionnaire, only nausea did not show any significance. Headache, lightheadedness, visual difficulties, shortness of breath, palpitation, confusion, and difficult communication showed statistically significant difference between preand post-values $(<p 0.05$, for all) (Table 3$)$.

\section{Discussion}

The main transmission route of the new global threat COVID19 is droplets, but during aerosol-generating procedures, airborne transmission may occur [8]. Airborne precautions include protective filtering FFR especially during aerosolgenerating procedures [1-8].

Despite widespread use in the past pandemics, today's pandemic, and industrial field occupations, there are few studies about the effects of FFR masks on respiratory functions and potential physiological effects of FFR masks $[1,2,9,10]$. To the best of our knowledge, among these studies, there is no study based on

Table 2 Venous blood gas parameters of ENT doctors before and after wearing mask

\begin{tabular}{llll}
\hline & \multicolumn{2}{l}{ Study group $(n=15)$} & \\
\cline { 2 - 4 } & Pre- & Post- & $p$ \\
\hline $\mathrm{pH}$ & $7.38 \pm 0.3$ & $7.39 \pm 0.3$ & 0.686 \\
$\mathrm{pCO}_{2}$ & 45.114 .7 & $45.17 \pm 5.9$ & 0.968 \\
$\mathrm{pO}_{2}$ & $35.28 \pm 10.68$ & $35.26 \pm 11.54$ & 0.996 \\
$\mathrm{Hct}$ & $43.06 \pm 5.52$ & $42.93 \pm 4.92$ & 0.546 \\
$\mathrm{Hb}$ & $14.5 \pm 1.94$ & $14.32 \pm 1.98$ & 0.108 \\
$\mathrm{SpO}_{2}$ & $53.06 \pm 9.88$ & $51.28 \pm 10.8$ & 0.09 \\
$\mathrm{HCO}_{3}$ & $26.68 \pm 1.67$ & $26.88 \pm 1.53$ & 0.708 \\
$\mathrm{Lactate}$ & $1.077 \pm 0.18$ & $1 \pm 0.24$ & 0.395 \\
\hline
\end{tabular}

The value of $p \leq 0.05$ was considered statistically significant 
Fig. 1 Bar graph with confidence intervals of mean $\mathrm{pCO}_{2}$ values between before and after mask wearing

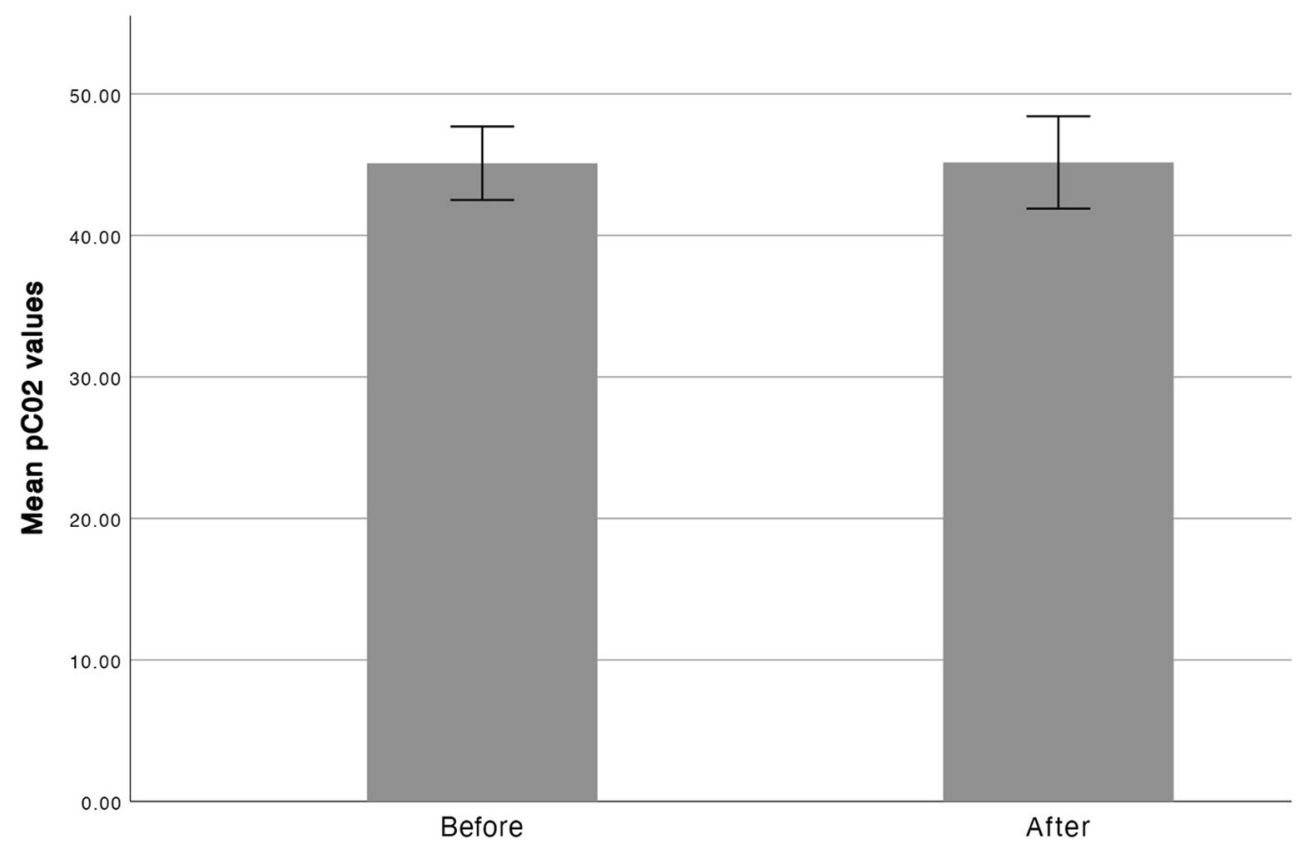

peripheral venous blood gas analysis, and our study is the first in this respect. Arterial blood gas analysis (ABG) is the gold standard method for assessment of oxygenation and acid base analysis. Although ABG analysis remains the gold standard, VBG analysis has been shown to correlate with $\mathrm{ABG}$ analysis and has been proposed as a safer less invasive alternative to ABG analysis. Therefore, we evaluate the effect of mask on respiratory functions by VBG [11, 12].

In a study on healthy pregnant women working by wearing an FFR, no significant physiologic or subjective response was observed after 1-h exercise and sedentary activities compared with non-pregnant women [10]. In another study conducted among pregnant employees wearing N95 mask, the oxygen uptake was found decreased, and carbon dioxide production was found increased. As a result of this study, the authors suggested using less resistant masks and more frequent breaks [10].

Roberge et al. assessed the physiological impact of the N95 FFR on healthcare workers [7]. They reported that in healthy healthcare workers FFR did not impose any important physiological burden during $1 \mathrm{~h}$ of use at realistic clinical work
Fig. 2 Bar graph with confidence intervals of mean $\mathrm{pO}_{2}$ values between before and after mask wearing

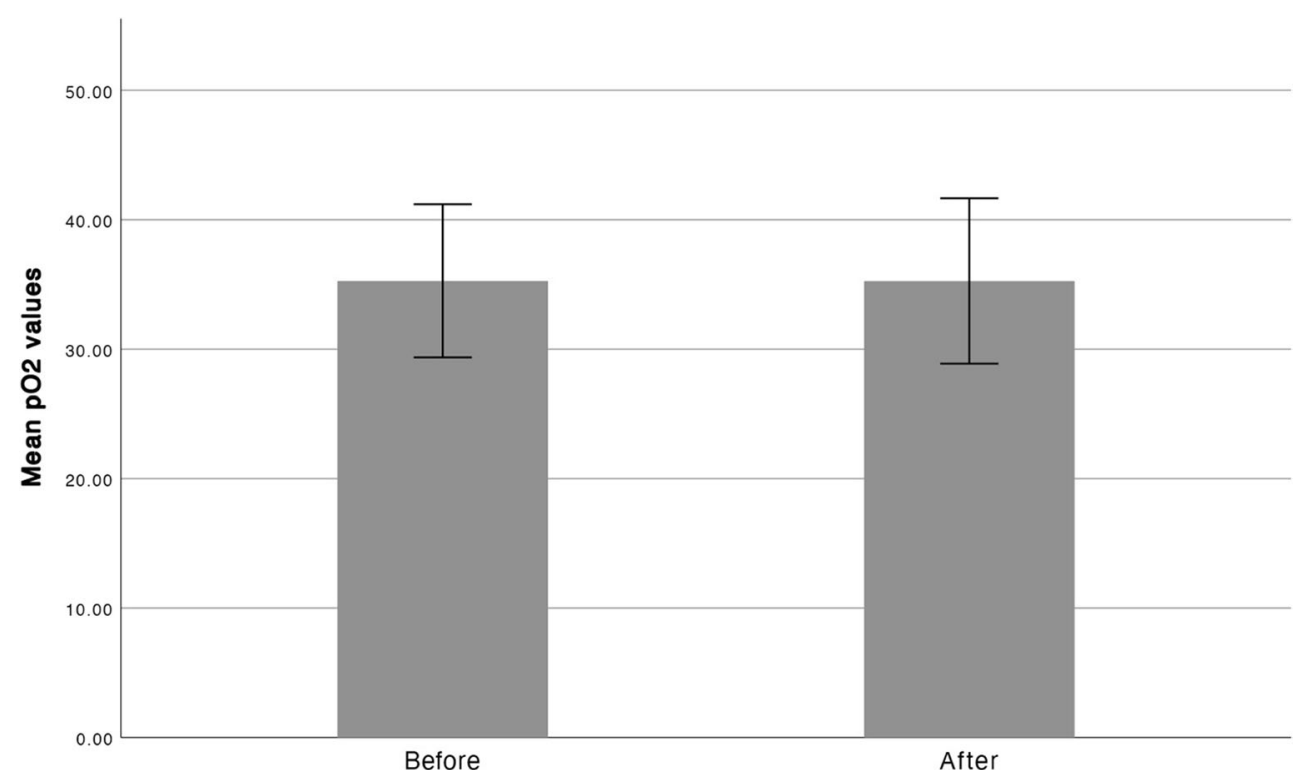


Table 3 Roberge subjective symptom scores according to wearing masks in ENT doctors

\begin{tabular}{llllll}
\hline & $\begin{array}{l}\text { Mean difference } \\
\text { (mean pre-post values) }\end{array}$ & Std deviation & \multicolumn{2}{l}{$\begin{array}{l}\text { 95\% confidence interval of the } \\
\text { difference }\end{array}$} & \\
\cline { 3 - 5 } & & & Lower & Upper \\
Nausea & - & - & - & - & $N S$ \\
Headache & -1.466 & 0.915 & -1.97 & -0.95 & 0.000 \\
Lightheadedness & -0.73 & 0.96 & -1.26 & -0.2 & 0.01 \\
Visual difficulties & -1.66 & 0.89 & -2.16 & -1.16 & 0.000 \\
Shortness of breath & -1.93 & 0.88 & -2.42 & -1.44 & 0.000 \\
Palpitation & -0.6 & 0.82 & -1.05 & -0.14 & 0.014 \\
Confusion & -0.33 & 0.48 & -0.6 & -0.06 & 0.019 \\
Difficult communication & -2.4 & 0.5 & -2.68 & -2.11 & 0.000 \\
\hline
\end{tabular}

The value of $p \leq 0.05$ was considered statistically significant

$N S$ not significant rates, but FFR dead-space carbon dioxide and oxygen levels were significantly above and below respectively (which were obtained via a line attached to a port in FFR and analyzed).

Rebmann et al. investigated the physiological and other effects and compliance of long-term respiratory (N95) use among medical intensive care unit nurses and reported that long-term use of respiratory protection did not result in any clinically relevant physiologic burden for health care personal [2]. An interesting finding from this study is that although the nurses did not experience any clinically significant negative physiologic effect from wearing respiratory protection, they reported many subjective symptoms. For example, perceived shortness of breath increased over time [2]. There is also another research reporting that headache developed as a result of N95 face mask [9].

In our research as a result of VBG analysis performed at the beginning and end of $4 \mathrm{~h}$ of FFP3 mask use, we did not find any statistically significant difference in the following parameters which we analyzed: $\mathrm{pH}, \mathrm{pCO}_{2}, \mathrm{pO}_{2}, \mathrm{Hct}, \mathrm{Hb}, \mathrm{SpO}_{2}$, $\mathrm{HCO}_{3}$, lactate. Although there is not any $\mathrm{VBG}$ analysis in the literature, these findings are compatible with the other studies mentioned above.

In addition, as a result of questionary in which we investigated subjective symptoms, we found that symptoms such as headache, lightheadedness, visual difficulties, shortness of breath, palpitation, confusion, and difficult communication were found increased significantly with the use of masks.

Lack of prolonged mask wearing may be a limitation of the study. FFP3 masks had to be removed at lunch break. In our study, none of the participants took off their masks during the 4-h period in order not to interrupt the workflow.

At the beginning of this research, we planned that if we detect a significant change in blood gases as a result of FFP3 use, we will continue to the research with valved mask and surgical masks. However, when we found the results like this, we abandoned the research at this stage because bloodletting is an invasive procedure even though it does not cause any important complications.

\section{Conclusion}

Due to our research, 4-h use of FFP3 mask did not cause any significant VBG change. Although the participants complained about some subjective symptoms, this study indicated that long-term use of FFP3 mask did not cause any significant discomforts and it was well tolerated.

Authors' contributions All authors contributed to the design, data collection, analysis, and final version of the study.

\section{Compliance with ethical standards}

Ethics approval and consent to participate Ethical approval was taken from the local ethical committee.

Conflict of interest The authors declare that they have no conflict of interest.

\section{References}

1. Tong PS, Kale AS, Ng K et al (2015) Respiratory consequences of N95-type Mask usage in pregnant healthcare workers-a controlled clinical study [published correction appears in Antimicrob Resist Infect Control. 2016;5:26]. Antimicrob Resist Infect Control 4:48. https://doi.org/10.1186/s13756-015-0086-Z

2. Rebmann T, Carrico R, Wang J (2013) Physiologic and other effects and compliance with long-term respirator use among medical intensive care unit nurses. Am J Infect Control 41(12):1218-1223. https://doi.org/10.1016/j.ajic.2013.02.017

3. Islamoglu Y, Gemcioglu E, Ates I (2020) Objective evaluation of the nasal mucosal secretion in COVID-19 patients with anosmia [published online ahead of print, 2020 Oct 19]. Ir J Med Sci 1-3. https://doi.org/10.1007/s11845-020-02405-1 
4. Lee SA, Hwang DC, Li HY et al (2016) Particle size-selective assessment of protection of European standard FFP respirators and surgical masks against particles-tested with human subjects. J Healthc Eng 2016:8572493. https://doi.org/10.1155/2016/8572493

5. Long KD, Woodburn EV, Berg IC et al (2020) Measurement of filtration efficiencies of healthcare and consumer materials using modified respirator fit tester setup. PLoS One 15(10):e0240499. https://doi.org/10.1371/journal.pone.0240499

6. Radonovich LJ Jr, Cheng J, Shenal BV et al (2009) Respirator tolerance in health care workers. JAMA 301(1):36-38. https://doi. org/10.1001/jama.2008.894

7. Roberge RJ, Coca A, Williams WJ et al (2010) Physiological impact of the N95 filtering facepiece respirator on healthcare workers. Respir Care 55(5):569-577

8. Azap A, Erdinç FȘ (2020) Medical mask or N95 respirator: When and how to use?. Turk J Med Sci 50(SI-1):633-637. https://doi.org/ 10.3906/sag-2004-199
9. Lim EC, Seet RC, Lee KH et al (2006) Headaches and the N95 facemask amongst healthcare providers. Acta Neurol Scand 113(3):199202. https://doi.org/10.1111/j.1600-0404.2005.00560.x

10. Roberge RJ, Kim JH, Powell JB (2014) N95 respirator use during advanced pregnancy. Am J Infect Control 42(10):1097-1100. https://doi.org/10.1016/j.ajic.2014.06.025

11. Zeserson E, Goodgame B, Hess JD et al (2018) Correlation of venous blood gas and pulse oximetry with arterial blood gas in the undifferentiated critically Ill patient. J Intensive Care Med 33(3):176-181. https://doi.org/10.1177/0885066616652597

12. Awasthi S, Rani R, Malviya D (2013) Peripheral venous blood gas analysis: An alternative to arterial blood gas analysis for initial assessment and resuscitation in emergency and intensive care unit patients. Anesth Essays Res 7(3):355-358. https://doi.org/10.4103/ 0259-1162.123234

Publisher's note Springer Nature remains neutral with regard to jurisdictional claims in published maps and institutional affiliations. 